\title{
Dinâmica da água em áreas de recarga de nascentes em dois ambientes na Região Alto Rio Grande, Minas Gerais
}

\author{
Water dynamics in springs recharge areas in two \\ environments in the alto Rio Grande Region, Minas Gerais
}

Alisson Souza de Oliveira ${ }^{1 *}\left(\mathbb{D}\right.$, Antônio Marciano da Silva' ${ }^{\circledR}$, Carlos Rogério de Mello ${ }^{1}$

\begin{abstract}
RESUMO
Apesar da importância da água na Terra, pouco se conhece sobre sua dinâmica no solo e, consequentemente, poucas são as informações sobre sua preservação em quantidade e qualidade. Diante disso, objetivou-se, neste trabalho, gerar informações que dessem subsídio ao entendimento da dinâmica da água no solo em áreas de recarga de nascentes. Para tanto, realizou-se o monitoramento da vazão e da precipitação nas áreas de recarga de duas pertencentes, verificando a relação existente entre os atributos físico-hídricos do solo intimamente relacionados à recarga subterrânea, além das características pedológicas, do uso do solo, da cobertura vegetal e da declividade. Os resultados mostraram que a sinalização de que os Cambissolos apresentam maior capacidade de infiltração e, consequentemente, recarga, em relação aos Latossolos, não se confirmou neste trabalho. Mesmo havendo uma grande discrepância nas classes de relevo entre as áreas de recarga das nascentes, esse efeito não foi suficiente para reduzir o processo de recarga. As condições de uso do solo não foram substancialmente diferentes a ponto de influenciar o processo de infiltração. O grande diferencial entre as áreas de recarga das nascentes em relação à capacidade de gerar deflúvio base se explica pelos atributos físico-hídricos e pelo índice pluviométrico, que, neste caso, resultaram em uma associação mais efetiva na área da nascente L1. A elevada capacidade de retenção de água no Latossolo, reflexo da maior microporosidade associada a sua maior profundidade, é uma característica desfavorável para o processo de recarga quando comparado ao Cambissolo, que tem horizonte B incipiente e menores profundidades.

Palavras-chave: área de recarga de nascentes; recarga do lençol superficial; escoamento de base.
\end{abstract}

\begin{abstract}
Despite the importance of water on earth, little is known about its dynamics in the soil, and consequently, there is little information about its preservation in quantity and quality. Therefore, the objective of this research was to generate information to support the understanding of water dynamics in soil springs in recharge areas. Thus, we carried out monitoring flow and precipitation in the areas of two belonging clearance, verifying the relationship between the physical and water attributes of the soil closely related to groundwater recharge, in addition to soil characteristics, land use, cover vegetation and slope. The results showed that the signaling that Cambisoils have higher infiltration capacity and consequently clearance in relation to Latosols was not confirmed in this study. Even though there is a large discrepancy in relief classes between the recharge areas of springs, this effect was not sufficient to reduce the recharge process. Land use conditions were not substantially different as to influencing the infiltration process. The big difference between the recharge areas of the springs on the ability to generate runoff base is explained by physical-water attributes and rainfall, which in this case resulted in a more effective association in the area of spring L1. The higher water retention capacity of the Oxisol, reflecting the higher microporosity associated with its greater depth, is an unfavorable feature for the recharge process, when compared to Inceptisol, which has an incipient B horizon and lower depths.
\end{abstract}

Keywords: springs recharge area; recharge surface groundwater; base flow. 


\section{INTRODUÇÃO}

$\mathrm{Na}$ atualidade, um dos grandes desafios da humanidade é a triste realidade de conviver com a escassez de água decorrente ora do uso excessivo, ora da baixa qualidade dos corpos hídricos.

A exploração desordenada desse recurso vem provocando inúmeros problemas ambientais, principalmente em áreas de recarga de nascentes, causando alterações na quantidade e na qualidade da água drenada. Como consequência, a água potável de fácil acesso, relativamente escassa, será um dos principais problemas ambientais a serem enfrentados pela população mundial nas próximas décadas. Para que se tenha o uso sustentável desse recurso, é necessário compreender como ocorrem os processos que promovem a recarga subterrânea dessa água e os fatores que a influenciam, para uma melhor gestão desses recursos.

De maneira geral, as modificações decorrentes das atividades antrópicas causam redução na disponibilidade de água por provocarem estiagens severas, inundações e destruições, produção e transporte de sedimentos, prejudicando as atividades agrícolas, além de possibilitar $o$ aporte de nutrientes em mananciais com influência direta na qualidade da água (ANDRADE; MELLO; BESKOW et al., 2013).

A qualidade e a quantidade da água de uma nascente podem ser alteradas por diversos fatores, destacando-se o clima, o relevo, as classes de solos, a cobertura vegetal e o uso do solo (KEESE; SCANLON; REEDY, 2005; MENEZES et al., 2009), além da profundidade do solo (ARNOLD et al., 2000; MENEZES et al., 2009).

A redução dessa disponibilidade está relacionada principalmente à diminuição da infiltração da água no solo, aumentando o escoamento superficial direto, prejudicando o processo de recarga do lençol superficial. Tal fato é frequentemente atribuído às alterações dos atributos físico-hídricos, como, por exemplo, densidade do solo, macro e microporosidade e condutividade hidráulica, atributos intimamente ligados ao processo de infiltração e recarga (RIZZARDI et al., 2014). Vale ressaltar também a influência do relevo no processo de infiltração: de maneira geral, quanto mais declivoso, menor o tempo de oportunidade para que ocorra o processo de infiltração e recarga do lençol superficial, contribuindo para a redução da disponibilidade. Outro fator a se destacar são os diferentes tipos de solo que influenciarão os valores dos atributos físico-hídricos do solo. Com relação à cobertura vegetal, solos que apresentam vegetação de grande porte (mata nativa ou plantada), de maneira geral, têm melhores condições para os processos de infiltração e, consequentemente, recarga do lençol superficial (OLIVEIRA et al., 2014).

No Brasil, apesar do aumento no número de investimentos em pesquisas em recursos hídricos, o conhecimento sobre as variáveis hidrológicas por meio de redes de monitoramento ainda é limitado, principalmente no que tange aos estudos a respeito dos mananciais subterrâneos (MESTRINHO, 2008).

Nesse sentido, o conhecimento sobre a dinâmica da água em áreas de recarga de nascentes é de suma importância, pois fornecerá informações relevantes sobre o manejo e a conservação desse recurso, dando subsídios à tomada de decisão no sentido de promover o seu uso racional e sem prejuízos às atividades antrópicas.

Diante do exposto, objetivou-se, neste trabalho, avaliar a dinâmica do escoamento nas áreas de recarga das nascentes L1 e M1, inseridas, respectivamente, nas Bacias Hidrográficas dos Ribeirões Lavrinha (ambiente Serra da Mantiqueira) e Marcela (ambiente Campo das Vertentes), na Região Alto do Rio Grande, a montante da Usina Hidrelétrica (UHE) de Camargos, da Companhia Energética de Minas Gerais (CEMIG).

\section{MATERIAL E MÉTODOS}

\section{Localização e caracterização das áreas de recarga das nascentes nos ambientes da Serra da Mantiqueira e Campo das Vertentes, Região Alto Rio Grande (GD1)}

O trabalho foi desenvolvido em duas nascentes cujas áreas de recarga estão inseridas nas Bacias Hidrográficas dos Ribeirões Lavrinha (ambiente Serra da Mantiqueira) e Marcela (ambiente Campo das Vertentes), ambas pertencentes à Unidade de Planejamento e Gestão de Recursos Hídricos do Alto Rio Grande (UPGRH-GD1), em Minas Gerais, sendo suas localizações apresentadas na Figura 1.

A área de recarga da nascente L1 está inserida na Bacia Hidrográfica do Ribeirão Lavrinha, a qual deságua diretamente no Rio Grande, localizada na cidade de Bocaina de Minas, Minas Gerais. Está posicionada entre as coordenadas N 7554424 m, E 553831 m e N 7551361 m, E 557856 m, fuso $45^{\circ} \mathrm{WGr}$, no sistema de projeção UTM e Datum SAD69, ao sul da UPGRH-GD1, na Serra da Mantiqueira. Essa bacia tem área de 676 ha, com altitudes variando de 1.144 a $1.738 \mathrm{~m}$, sendo sua altitude e declividade médias, respectivamente, de 1.375 m e 38,5\% (SILVA, 2009). A classificação preliminar de seu clima foi $\mathrm{ArB}_{2}$ a', significando um clima superúmido, com reduzido ou nenhum déficit de água, mesotérmico e com pouca variação de calor ao longo do ano, isto é, tem excedente hídrico considerável, contribuindo para a geração de deflúvio superficial na região (YANAGI, 2008). A temperatura média no mês mais quente e no mês mais frio são de 19 e $11^{\circ} \mathrm{C}$, respectivamente, com ocorrência de geadas.

A área de recarga da nascente M1 está inserida na Bacia Hidrográfica do Ribeirão Marcela, desaguando no Córrego Jaguara, que, por sua vez, deságua diretamente no reservatório da UHE de Camargos da CEMIG, localizada no município de Nazareno. A bacia está compreendida entre as coordenadas N 7651088 m, E 550202 m e N 7648410 m, E 552724 $\mathrm{m}$, fuso $45^{\circ} \mathrm{WGr}$, no sistema de projeção UTM e Datum SAD69, localizando-se mais ao norte da UPGRH-GD1. Essa bacia tem uma área de 470 ha, com altitudes variando de 955 a $1.059 \mathrm{~m}$, sendo sua altitude e declividade médias, respectivamente, de $1.007 \mathrm{~m}$ e 12,3\% (SILVA, 2009). A classificação preliminar do seu clima foi $\mathrm{B}_{1} \mathrm{rB}_{3} \mathrm{a}^{\prime}$, o que representa 
uma área de clima úmido, com uma pequena deficiência hídrica nos meses de abril a setembro (YANAGI, 2008). A precipitação e a temperatura médias anuais são, respectivamente, de $1.300 \mathrm{~mm}$ e $19,7^{\circ} \mathrm{C}$, com ocorrência de temperaturas máxima e mínima diárias ao longo do ano de 36,2 e $2,6^{\circ} \mathrm{C}$. A classificação climática sinaliza um índice de umidade que supera a evapotranspiração, porém o excedente hídrico não é tão expressivo quanto o observado na área de recarga da nascente L1.

Na Tabela 1 são apresentadas as características de solo, relevo, declividade e uso predominante das áreas de recarga das nascentes L1 e M1.

\section{Monitoramento da vazão, precipitação e caracterização do regime de escoamento}

A vazão foi monitorada com a utilização de medidor de vazão modelo WSC Flume, o qual deve ser instalado no solo em nível no plano horizontal, tanto longitudinal quanto transversalmente, no qual, após estabilização do nível d'água sobre a calha, é realizada a leitura deste, com o auxílio de uma régua e posteriormente convertido em vazão
$\left(\mathrm{L} \cdot \mathrm{s}^{-1}\right)$, por meio de uma equação específica para cada calha utilizada. A frequência de monitoramento foi aproximadamente quinzenal, no período entre outubro de 2009 e setembro de 2012, sendo que, sempre, a vazão medida correspondeu ao escoamento de base (surgência da nascente), não havendo contribuição do escoamento superficial direto. Também foi realizada a quantificação da precipitação ocorrida no período com utilização de um pluviômetro tipo Ville de Paris instalado nas áreas de recarga de cada nascente.

O deflúvio gerado pelas nascentes no estudado foi estimado com base na integração numérica dos dados de vazão.

\section{RESULTADOS E DISCUSSÃO}

\section{Análises do regime do escoamento: deflúvio}

A partir da análise dos dados da Tabela 2, percebe-se que na área de recarga da nascente $\mathrm{L} 1$, em todos os anos hidrológicos, ocorreu um
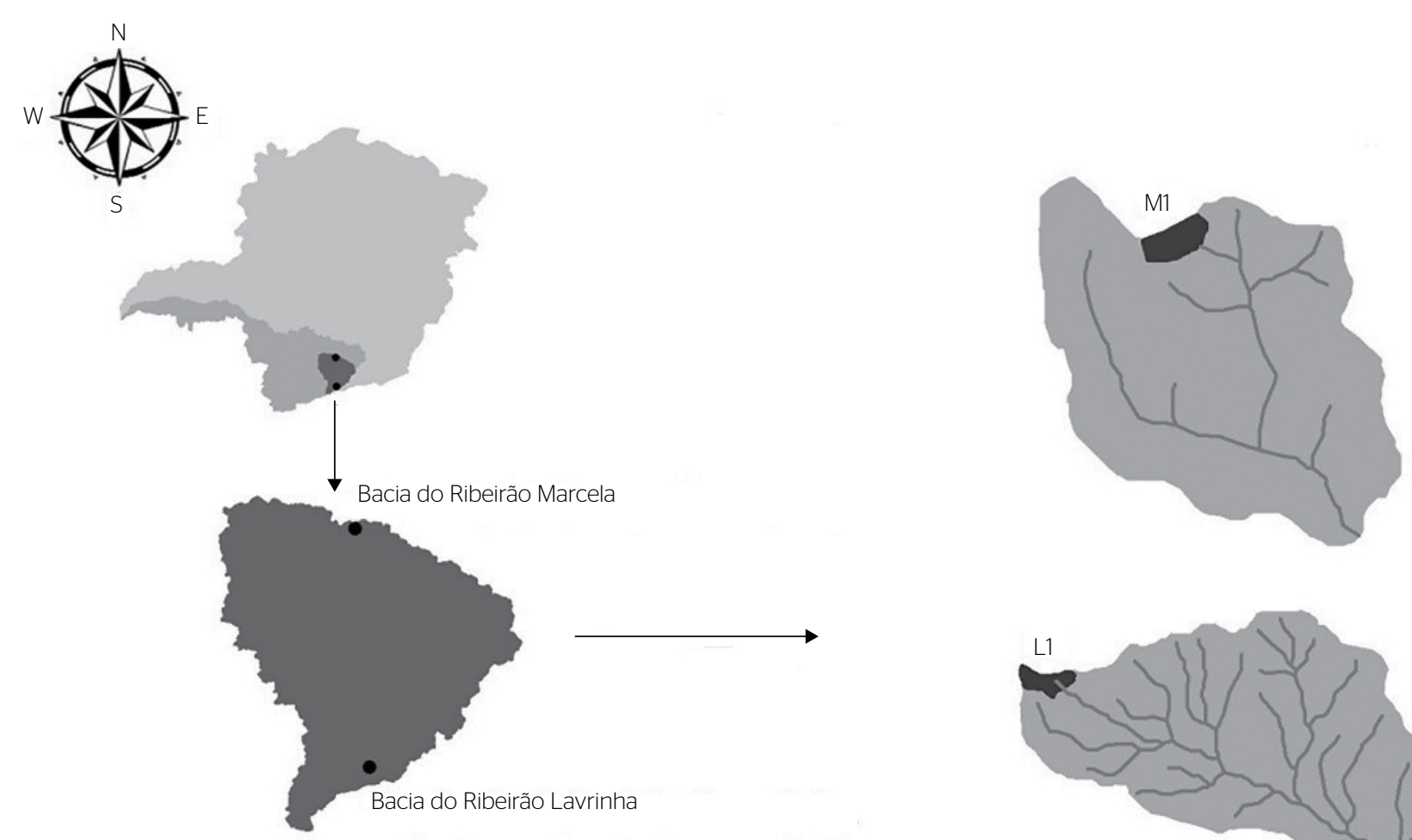

Estado de Minas Gerais

Bacia Hidrográfica do Rio Grande

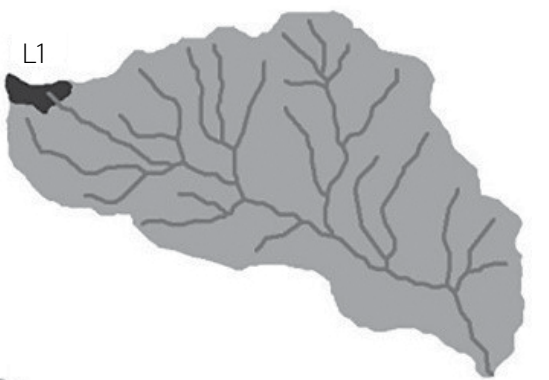

Área da bacia do Ribeirão Marcela

UPGRH - GD 1

Área da bacia do Ribeirão Lavrinha

Figura 1 - Localização das Bacias Hidrográficas dos Ribeirões Lavrinha e Marcela no Estado de Minas Gerais, no GD1, e das nascentes L1 e M1, nas respectivas bacias. 
total de chuva superior ao ocorrido na área de recarga da nascente M1 e, consequentemente, maior potencialidade para gerar escoamento.

Em termos relativos, a maior capacidade da área de recarga da nascente L1 gerar escoamento é comprovada quando se analisa a relação deflúvio base/precipitação (Db/P), que, em média, foi de 36,52\%; já na

Tabela 1 - Distribuição das classes de solos, relevo, declividade média e uso predominante do solo nas áreas de recarga das nascentes L1 e M1.

\begin{tabular}{|c|c|c|}
\hline & \multicolumn{2}{|c|}{ Área de recarga das nascentes } \\
\hline & L1 & M1 \\
\hline Classe de solos* & $\begin{array}{l}\text { Cambissolo } \\
\text { CX A } \\
\text { Fraco forte } \\
\text { ondulado }\end{array}$ & $\begin{array}{c}\text { Predominância } \\
\text { Latossolo } \\
\text { Vermelho } \\
\text { Amarelo }\end{array}$ \\
\hline Area recarga $(\text { ha })^{\star \star}$ & 7,24 & 9,14 \\
\hline Classes de relevo** & \multicolumn{2}{|c|}{$\begin{array}{l}\text { Distribuição das } \\
\text { classes de relevo (\%) }\end{array}$} \\
\hline Fortemente montanhoso (> 75\%) & 0,1 & - \\
\hline Montanhoso (45-75\%) & 10,9 & 2,1 \\
\hline Fortemente ondulado (2O-45 \%) & 67,2 & 22,1 \\
\hline Ondulado (8-20\%) & 19,5 & 65,6 \\
\hline Suavemente ondulado (3-8\%) & 1,6 & 9,5 \\
\hline Plano (O-3\%) & 0,7 & 0,7 \\
\hline Declividade média (\%) & 28,7 & 17,0 \\
\hline \multicolumn{3}{|l|}{ Uso predominante (\%)** } \\
\hline Pastagem & 92,9 & 66,7 \\
\hline Samambaia & 6,9 & - \\
\hline Mata nativa & 0,2 & 0,2 \\
\hline BR 265 & - & 7,8 \\
\hline Milho & - & 22,4 \\
\hline Várzea & - & 2,9 \\
\hline
\end{tabular}

Fonte: *Menezes et al. (2009); **Silva (2009).

Tabela 2 - Análise do regime de escoamento das áreas de recarga das nascentes L1 e M1.

\begin{tabular}{l|c|c|c}
\multicolumn{4}{|c}{ Análise do escoamento } \\
\hline \multirow{2}{*}{ Nascente L1 } & Out. 2009 - & Out. 2010 - & Out. 2011 - \\
\cline { 2 - 4 } & Set. 2010 & Set. 2011 & Set. 2012 \\
\hline \multirow{2}{*}{ P (mm) } & $1.879,08$ & $1.360,98$ & $1.704,34$ \\
\hline Db (mm/ano) & 506,51 & 649,34 & 594,83 \\
\hline Db/P (\%) & 26,96 & 47,71 & 34,9 \\
\hline \multirow{2}{*}{ Nascente M1 } & Out. 2009 - & Out. 2010 - & Out. 2011 - \\
\cline { 2 - 4 } & Set. 2010 & Set. 2011 & Set. 2012 \\
\hline \multirow{2}{*}{ P (mm) } & $1.227,91$ & $1.331,7$ & $1.413,14$ \\
\hline Db (mm/ano) & 245,39 & 207,57 & 274,26 \\
\hline Db/P (\%) & 19,98 & 15,59 & 19,41 \\
\hline
\end{tabular}

P: precipitação; Db: deflúvio base. área de recarga da nascente M1 essa relação foi de 18,33\%, mostrando maior eficiência no processo de infiltração e de recarga subterrânea na área de recarga da nascente L1.

Embora o ano hidrológico 2009/2010 tenha apresentado o maior volume de chuva entre os anos analisados, o deflúvio base não correspondeu na mesma proporção, pois apresentou um dos menores valores. Uma possível explicação pode ser obtida quando se analisa a Figura 2A, na qual se evidencia concentração dos totais acumulados de chuvas em intervalos de tempo curtos, o que favorece o deflúvio superficial direto e concorre com o processo de infiltração e recarga. Outro possível condicionante para tal situação é a umidade antecedente do solo, caso esta esteja muito baixa, também concorrerá com o processo de recarga e sustentação do deflúvio de base.

Para o ano hidrológico 2010/2011, embora tenha ocorrido diminuição do total de chuva em relação ao ano anterior, houve aumento no deflúvio base, indicando uma melhor distribuição das chuvas. Pela análise da Figura 2B, verifica-se que a precipitação máxima acumulada foi de $221 \mathrm{~mm}$, enquanto no ano anterior ocorreram vários eventos, com total acima de $200 \mathrm{~mm}$.

No ano hidrológico 2011/2012 ocorreu uma situação intermediária entre os anos 2009/210 e 2010/2011, com algumas precipitações elevadas em curtos períodos, porém com menor frequência, resultando em um valor ainda relativamente alto para a relação $\mathrm{D}_{\mathrm{b}} / \mathrm{P}$ (Figura $2 \mathrm{C}$ ).

Com relação à área de recarga da nascente M1, o ano hidrológico 2009/2010 apresentou um dos menores totais de chuva, porém o segundo maior deflúvio base, além de um valor médio superior aos demais anos. O que pode ter contribuído para o deflúvio mais elevado foi a melhor distribuição temporal das chuvas (Figura 3A).

Para o ano hidrológico 2010/2011, ocorreu aumento no total de chuvas, mas houve redução no deflúvio em relação ao ano anterior. Analisando-se a Figura 3B é possível perceber pontos com elevados valores de chuva e que contribuíram para um menor tempo de oportunidade para que ocorresse o processo de infiltração e recarga, e, consequentemente, para a redução do deflúvio base.

No ano hidrológico 2011/2012 houve atraso no início do período chuvoso, que se prolongou até o mês de julho. Tal fato, aliado a melhor distribuição temporal das chuvas, contribuiu para que ocorresse o maior deflúvio de base entre os anos hidrológicos analisados (Figura 3C).

A análise simultânea do ocorrido nas duas áreas de recarga das nascentes permite constatar que no ano hidrológico 2009/2010, Figuras 2A e $3 \mathrm{~A}$, as chuvas concentraram-se entre os meses de outubro a março em ambas as áreas. Outro aspecto importante a ser analisado é a resposta imediata no deflúvio base aos eventos de precipitação. Na área de recarga da nascente L1 ocorre a elevação do deflúvio base em praticamente todos os eventos de precipitação monitorados. Esse fato é justificado pela menor profundidade do Cambissolo presente na área associado à maior infiltração e redistribuição da água, favorecendo a 
recarga mais rápida do aquífero, quando comparado à área de recarga da nascente M1, que apresenta menor efetividade na redistribuição da água, além de um solo muito profundo, o Latossolo.

Embora a área de recarga da nascente L1 apresente maiores totais precipitados, melhor distribuição das chuvas e maiores valores de deflúvios, verifica-se menor capacidade de regularização natural dos deflúvios do que na área de recarga da nascente M1. Fato percebido quando se analisa a decomposição dos deflúvios nos períodos de recarga e depleção, em que, em média, $60 \%$ do deflúvio total é drenado no período de recarga; já na área de recarga da nascente M1 essa proporção é da ordem de 53\%, demonstrando melhor regularização. Além disso, ao final do ano hidrológico, há menor amplitude de variação do deflúvio em relação a sua média do que na área de recarga da nascente $\mathrm{L} 1$, o que pode ser atribuído à maior capacidade de retenção de água pelo Latossolo, promovendo uma drenagem mais eficiente ao longo do tempo.

Nos demais anos hidrológicos, a análise desenvolvida também se aplica, pois os valores dos indicadores praticamente se repetem.

Nas Tabelas 2 e 3 são apresentadas algumas características relevantes presentes nas áreas das duas nascentes, cuja análise permite

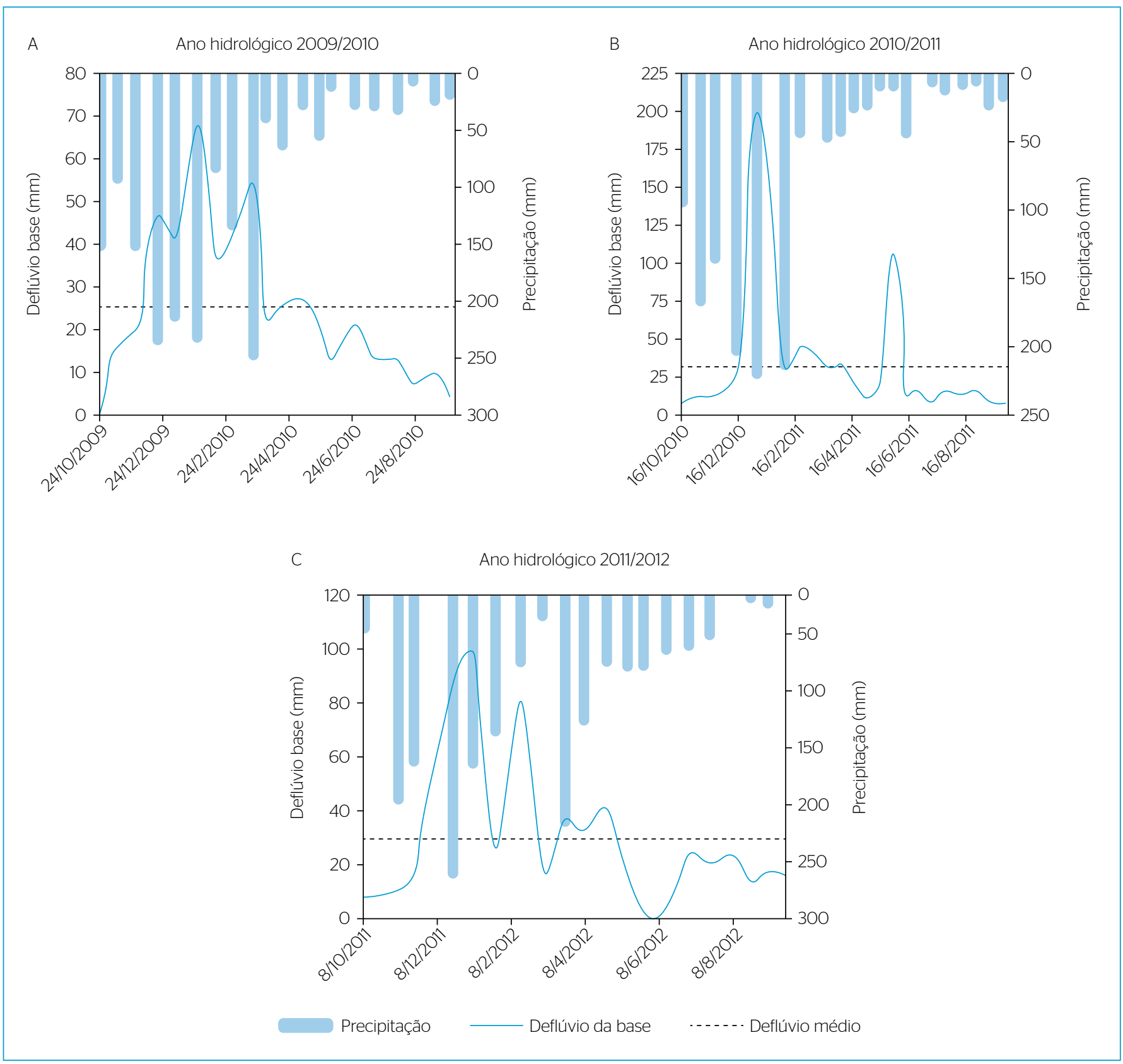

Figura 2 - Hidrograma e hietograma para os anos hidrológicos 2009/2010 (A), 2010/2011 (B) e 2011/2012 (C) na área de recarga da nascente L1. 
ter uma melhor compreensão do processo de geração de deflúvio nas duas áreas de recarga.

Com base na análise da Tabela 1, constata-se que os grandes diferenciais entre as áreas de recarga são a classe de solo e a declividade média. Sendo que, com base nessas características e no contexto pedológico, há um maior potencial da área de recarga da nascente M1 ser mais efetiva no processo de recarga do lençol d'água superficial, do que a área da nascente L1, pois os Latossolos em geral, são solos com maior capacidade de infiltração e estão associados a uma declividade média menor. Por outro lado, o Cambissolo, em geral, apresenta menor capacidade de infiltração, maior declividade, pouca profundidade e menor capacidade de armazenamento de água no solo (ALMEIDA; RESENDE, 1985; CURI; CHAGAS; GIAROLA, 1994; SANTOS et al., 1998), estando ainda associados a uma maior declividade média.

Com relação ao porte da área de recarga e uso do solo, as diferenças entre elas são menos significativas. O porte da área da nascente M1 é cerca de $26 \%$ maior do que o da L1, o que pode representar um reservatório maior e conferir à nascente M1 maior capacidade de regularização do escoamento quando comparado à nascente L1. Com relação à ocupação a área de recarga da nascente L1 apresenta 92,9\% de pastagem enquanto a área de recarga da nascente M1 66,7\%, que apresenta,

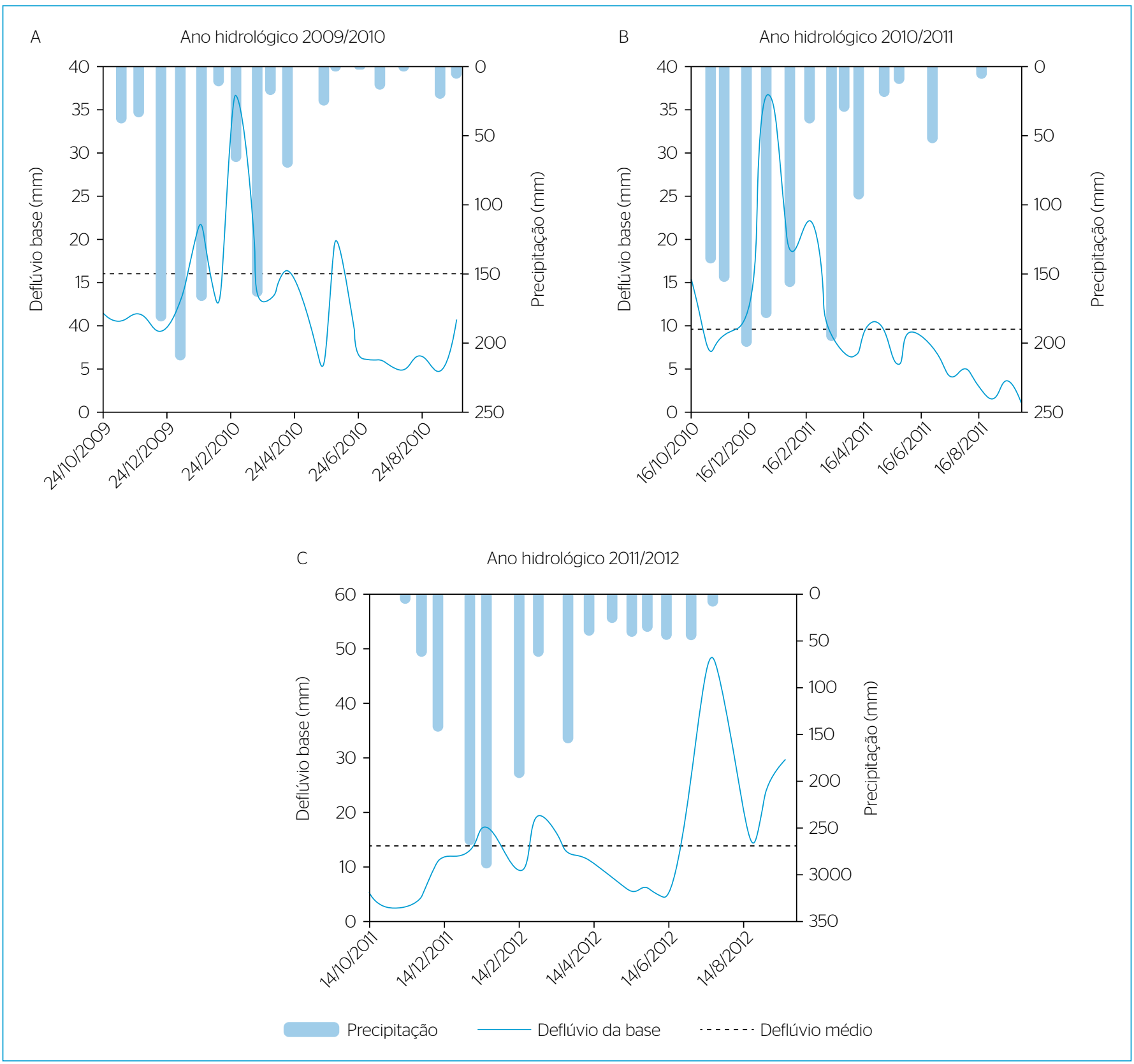

Figura 3 - Hidrograma e hietograma para os anos hidrológicos 2009/2010 (A), 2010/2011 (B) e 2011/2012 (C) na área de recarga da nascente M1. 
porém, $22,4 \%$ com cultura do milho, a qual permanece no campo por aproximadamente cinco meses, sendo no restante do tempo utilizada como pastagem. A porcentagem de mata nativa presente em ambas as áreas de recarga é de apenas $0,2 \%$, não havendo, portanto, nesse particular, diferenças significativas.

$\mathrm{Na}$ Tabela 3 são apresentados os valores médios dos atributos físico-hídricos, das camadas de solos presentes nas áreas das nascentes L1 e M1.

Os valores da porosidade drenável $(\mu)$ das diferentes camadas não diferem substancialmente quando são analisados comparativamente entre as duas nascentes. Esses valores aumentam à medida que se aprofunda no perfil do solo, em ambas as áreas de recarga, com exceção da camada de 60-80 cm na área de recarga da nascente $L 1$, onde ocorreu pequena redução em seu valor. Esse atributo tem relação direta com o movimento de água no solo e, por consequência, na infiltração e capacidade de recarga subterrânea.

Já a microporosidade $(\mathrm{M})$ tem relação oposta à porosidade drenável, ou seja, quanto maior seu valor, maior é o reservatório de água no perfil do solo, o que concorre com o processo de redistribuição e recarga, e, consequentemente, de sustentação do deflúvio base. A área de recarga da nascente L1 apresenta nas camadas, com exceção da camada de $0-20 \mathrm{~cm}$, valores menores do que os encontrados na área de recarga da nascente M1, o que proporciona menores retenções de água pela matriz do solo, permitindo uma drenagem mais eficiente e favorecendo o processo de recarga subterrânea. Um dos principais fatores para determinar essa diferença é a distribuição das unidades texturais dos solos. Os menores valores de microporosidade apresentados pelo Cambissolo na área de recarga da nascente L1 podem estar associados aos maiores teores de areia (de 52,33 a 57,75\%) e aos menores teores de argila (de 27,44 a 34,39\%). Enquanto o Latossolo presente na área de recarga da nascente M1 apresentou menores teores de areia (de 25,85 a 31,61\%) associados aos maiores teores de argila (de 50,99 a 54,13\%). Teores maiores de areia, em geral, resultam em solos com menor superfície de contato, menor retenção e maior facilidade para o processo de redistribuição da água no perfil. Por outro lado, teores maiores de argila e silte resultam em solos com maior superfície de contato, maior retenção de água e maior dificuldade para o processo de infiltração.

$\mathrm{Na}$ área de recarga da nascente L1, a densidade do solo aumenta à medida que se aprofunda no perfil do solo, fato consistente com as características do Cambissolo que ocorre na área, que é pouco intemperizado quando comparado ao Latossolo presente de na área de recarga da nascente $\mathrm{M} 1$, em que a densidade do solo diminui com a profundidade do perfil.

A matéria orgânica está presente em maiores quantidades em todas as camadas analisadas da área de recarga da nascente L1, apresentando

Tabela 3 - Valores médios do perfil para os atributos físico-hídricos do solo para as áreas de recarga das nascentes L1 e M1.

\begin{tabular}{|c|c|c|c|c|c|}
\hline L1 & $0-20 \mathrm{~cm}$ & $20-40 \mathrm{~cm}$ & $40-60 \mathrm{~cm}$ & $60-80 \mathrm{~cm}$ & $80-100 \mathrm{~cm}$ \\
\hline$\mu(\%)$ & 8,31 & 12,05 & 13,53 & 13,57 & 15,00 \\
\hline M (\%) & 44,70 & 35,45 & 37,05 & 36,03 & 36,19 \\
\hline Ds $\left(\mathrm{g} . \mathrm{cm}^{-3}\right)$ & 1,22 & 1,28 & 1,30 & 1,33 & 1,39 \\
\hline MO (Dag.kg-1) & 3,71 & 2,89 & 2,09 & 1,46 & 1,12 \\
\hline Silte (\%) & 12,50 & 12,33 & 13,54 & 15,41 & 13,81 \\
\hline Argila (\%) & 31,72 & 33,63 & 34,39 & 30,15 & 27,44 \\
\hline M1 & $0-20 \mathrm{~cm}$ & $20-40 \mathrm{~cm}$ & $40-60 \mathrm{~cm}$ & $60-80 \mathrm{~cm}$ & $80-100 \mathrm{~cm}$ \\
\hline$\mu(\%)$ & 10,10 & 11,60 & 14,06 & 15,14 & 15,41 \\
\hline MO (Dag.kg') & 3,01 & 2,34 & 1,68 & 1,23 & 0,95 \\
\hline Areia (\%) & 31,61 & 31,27 & 26,12 & 25,85 & 30,57 \\
\hline Silte (\%) & 17,21 & 17,84 & 18,84 & 17,77 & 16,35 \\
\hline Argila (\%) & 50,99 & 51,00 & 52,99 & 54,13 & 51,76 \\
\hline
\end{tabular}

Fonte: Oliveira (2015).

$\mu$ : porosidade drenável; M: microporosidade; $\mathrm{K}_{0}$ : condutividade hidráulica saturada; Ds: densidade do solo; MO: matéria orgânica. 
decréscimo à medida que se aprofunda no perfil do solo em ambas as áreas de recarga das nascentes. Ela é fator importante na estruturação e na condutividade hidráulica do solo.

A condutividade hidráulica saturada do solo apresentou valores mais elevados para a área de recarga da nascente L1, variando entre 1,08 e $2,27 \mathrm{~m} / \mathrm{dia}$, enquanto na área de recarga da nascente M1 os valores variaram entre 0,18 e 2,12 m/dia. À medida que se aprofunda no perfil do solo, os valores da condutividade hidráulica saturada do solo na área de recarga da nascente M1 reduzem, dificultando a percolação da água em profundidade e a recarga subterrânea. Esse comportamento está diretamente ligado aos atributos físico-hídricos: porosidade drenável, teor de areia e matéria orgânica, que se mostraram distintos entre as áreas, com valores superiores na área da nascente L1, o que explica a maior condutividade hidráulica ao longo perfil do solo.

Diante das análises apresentadas, pode-se destacar que, embora o solo presente na área de recarga da nascente L1 seja o Cambissolo, o que em termos pedológicos sinaliza para condições mais desfavoráveis à recarga do lençol superficial, ele converteu maior proporção do volume precipitado em deflúvio base. Apesar de haver uma grande discrepância nas classes de relevo entre as áreas de recarga das duas nascentes, sendo a área da nascente L1 mais acidentada, esse efeito não foi suficiente para reduzir o processo de recarga.

As condições de uso do solo não foram substancialmente diferentes a ponto de influenciar o processo de infiltração. O grande diferencial pode estar associado aos atributos físico-hídricos que influenciam a condutividade hidráulica saturada, que, neste caso, mostraram-se mais favoráveis na área da nascente L1, e à menor capacidade de retenção de água no perfil do Cambissolo.

Assim sendo, pode-se afirmar que a grande diferença entre as áreas de recarga das nascentes quanto à capacidade de gerar deflúvio base está relacionada aos atributos físico-hídricos e ao índice pluviométrico, que, neste caso, resultaram em uma associação mais efetiva na área da nascente L1.

Além disso, considerando-se a metodologia proposta por Souza (1993) e adaptada por Silva (2014), que classifica as regiões segundo sua potencialidade hidrológica para gerar deflúvio superficial, as áreas de recarga das nascentes L1 e M1 teriam tipologias correspondentes a 422 (precipitação anual acima de $1.500 \mathrm{~mm}$, declividade média de $28,7 \%$ e solo classe Cambissolo) e 333 (precipitação anual entre 1.200 e $1.500 \mathrm{~mm}$, declividade média de $17 \%$ e solo Latossolo Vermelho Amarelo), respectivamente. Portanto, o único fator em que L1 supera a M1 é o elevado índice pluvial, com relação às características de relevo e classe de solo, predominam condições potencialmente inferiores à geração de escoamento superficial. Entretanto, os resultados obtidos neste trabalho, bem como por Oliveira et al. (2014) e
Silva et al. (2012), mostram que as áreas de recarga das nascentes no ambiente Serra da Mantiqueira têm sido mais eficientes na formação de deflúvio superficial.

Um dos aspectos que vale destacar é que a metodologia de Souza (1993) tem caráter mais genérico e é recomendável em termos de planejamento, porém em termos de manejo há de se conhecer com detalhes as características do ambiente a ser trabalhado. Nesse caso, tomando-se como base as características dos atributos físico-hídricos do Cambissolo, em particular em relação a sua condutividade hidráulica e à porosidade drenável, seus valores são melhores do que os do Latossolo Vermelho Amarelo. Um fator que pode estar contribuindo para essa condição é o elevado teor de matéria orgânica. Tal situação de contradição reforça a necessidade de conhecer com detalhes e precisão esses atributos, pois o simples enquadramento pela classe de solo pode resultar em conclusões errôneas.

Dois aspectos devem ser incluídos nesta análise: o primeiro deles diz respeito à microporosidade e, portanto, à capacidade de retenção de água, que é maior no Latossolo e, nesse caso, em relação ao processo de recarga do lençol superficial, constitui-se em característica desfavorável; o segundo diz respeito à profundidade da camada de solo, que normalmente fica insaturada, e, portanto, a um reservatório que concorre com o processo de recarga. O Latossolo apresenta maior profundidade do que o Cambissolo, que tem horizonte B incipiente e profundidades menores (MENEZES et al., 2014). Portanto, considerando-se um regime pluvial mais favorável com elevado excedente hídrico, esse ambiente torna-se muito propício para gerar deflúvio, sobretudo o componente de base.

\section{CONCLUSÕES}

A sinalização de que os Cambissolos apresentam maior capacidade de infiltração de água no solo e, consequentemente, de recarga do lençol superficial, em relação aos Latossolos, não se confirmou neste trabalho. Mesmo havendo uma grande discrepância nas classes de relevo entre as áreas de recarga das nascentes, tal efeito não foi suficiente para reduzir o processo de recarga. As condições de uso do solo não foram substancialmente diferentes a ponto de influenciar o processo de infiltração. O grande diferencial entre as áreas de recarga das nascentes em relação à capacidade de gerar deflúvio base é explicado pelos atributos físico-hídricos e pelo índice pluviométrico, que, neste caso, resultaram em uma associação mais efetiva na área da nascente L1. A maior capacidade de retenção de água no Latossolo, reflexo da maior microporosidade associado à sua maior profundidade, é uma característica desfavorável para o processo de recarga do lençol superficial quando comparado ao Cambissolo, que tem horizonte B incipiente e menores profundidades. 


\section{REFERÊNCIAS}

ALMEIDA, J.R.; RESENDE, M. (1985) Considerações sobre o manejo de solos rasos desenvolvidos de rochas políticas no Estado de Minas Gerais. Informe Agropecuário, Belo Horizonte, v. 11, n. 128, p. 19-26.

ANDRADE, M.A.; MELLO, C.R.; BESKOW, S. (2013) Simulação hidrológica em uma bacia hidrográfica representativa dos Latossolos na região Alto Rio Grande, MG. Engenharia Agrícola e Ambiental, Campina Grande, v. 17, n. 1, p. 69-76. http://dx.doi. org/10.1590/S1415-43662013000100010

ARNOLD, J.G.; MUTTIAH, R.S.; SRINIVASAN, R.; ALLEN, P.M. (2O00) Regional estimation of base flow and groundwater recharge in the Upper Mississippi river basin. Journal of Hydrology, Amsterdã, v. 227, n. 1-4, p. 21-40. http://doi.org/10.1016/S0022-1694(99)00139-0

CURI, N.; CHAGAS, C.S.; GIAROLA, N.F.B. (1994) Distinção de ambientes agrícolas e relações solo-pastagens nos Campos da Mantiqueira (MG). In: EVANGELISTA, A.R.; CARVALHO, M.M.; CURI, N. (orgs.). Desenvolvimento de pastagens na zona fiiográfia Campos das Vertentes MG: reunião de trabalho sobre pastagens nativas e desenvolvimento de pastagens para o gado de leite das zonas dos Campos Vertentes. Lavras: ESAL. p. 21-43.

KEESE, K.E.; SCANLON, B.R.; REEDY, R.C. (2005) Assessing controls on diffuse groundwater recharge using unsaturated flow modeling. Water Resources Research, Oxford, v. 41, n. 6, p. 1-12. https://doi. org/10.1029/2004WR003841

MENEZES, M.D.; JUNQUEIRA JR., J.A.; MELLO, C.R.; SILVA, A.M.; CURI, N.; MARQUES, J.J. (2009) Dinâmica hidrológica de duas nascentes, associada ao uso do solo, características pedológicas e atributos físico-hídricos na sub-bacia hidrográfica do Ribeirão Lavrinha - Serra da Mantiqueira (MG). Scientia Forestalis, Piracicaba, v. 37, n. 82 , p. $175-184$

MENEZES, M.D.; SILVA, S.H.G.; MELLO, C.R.; OWENS, P.R.; CURI, N. (2014) Solum depth spatial prediction comparing conventional with knowledge-based digital soil mapping approaches. Scientia Agricola, São Paulo, v. 71, n. 4, p. 316-323.

MESTRINHO, S.S.P. (2008) Monitoramento em água subterrânea. In: FEITOSA, F.A.C. (org.). Hidrogeologia: conceitos e aplicações. Rio de Janeiro: CPRM. p. 673-685.
OLIVEIRA, A.S. (2015) Recarga subterrânea de nascentes em ambientes distintos da região Alto Rio Grande, MG. 165f. Tese (Doutorado em Recursos Hídricos em Sistemas Agrícolas) Universidade Federal de Lavras, Lavras.

OLIVEIRA, A.S.; SILVA, A.M.; MELLO, C.R.; ALVES, G.J. (2O14) Stream flow regime of springs in the Mantiqueira Mountain Range region, Minas Gerais State. Cerne, Lavras, v. 20, n. 3, p. 343-349. http://dx.doi. org/10.1590/01047760201420031268

RIZZARDI, A.S.; RIGHES, A.A.; KEMERICH, P.D.C.; SILVA, R.F.; SANTOS, S.A.; BORDA, W.F. (2014) Atributos físicos e fluxo de água em solos da bacia hidrográfica do rio Vacacaí-Mirim - RS. Monografias Ambientais, Santa Maria, v. 13, n. 5, p. 3690-3701. http://dx.doi. org/10.5902/2236130814260

SANTOS, D.; CURI, N.; FERREIRA, M.M.; EVANGELISTA, A.R.; CRUZ FILHO, A.B.; TEIXEIRA, W.G. (1998) Perdas de solo e produtividade de pastagens nativas melhoradas sob diferentes práticas de manejo. Pesquisa Agropecuária Brasileira, Brasília, v. 33, n. 2, p. $183-189$.

SILVA, A.L. (2014) Deflúvio superficial em Minas Gerias, caracterização e associação com os fatores físicos e ambientais. 134f. Tese (Doutorado em Recursos Hídricos em Sistemas Agrícolas) - Universidade Federal de Lavras, Lavras.

SILVA, L.A. (2009) Regime de escoamento e recarga subterrânea de nascentes na região do Alto Rio Grande, MG. 134f. Dissertação (Mestrado em Engenharia Agrícola) - Universidade Federal de Lavras, Lavras.

SILVA, L.A.; SILVA, A.M.; COELHO, G.; MELLO, C.R.; PEREIRA, D.R. (2012) Groundwater recharge estimate at Alto Rio Grande-MG watershed. Engenharia Agrícola, Jaboticabal, v. 32, n. 6, p. 1097-1108. http://dx.doi.org/10.1590/S0100-69162012000600011

SOUZA, S.M.T. (1993) Deflúvios superficiais no Estado de Minas Gerais. Belo Horizonte: Hidrossistemas.

YANAGI, S.M.N. (2008) Estruturação do banco de dados, análises e caracterização climática da região do Alto Rio Grande, MG. Lavras: FAPEMIG. 